\title{
El cuarto canto del Siervo. Un nuevo escenario de lectura
}

\author{
Dolores Aleixandre RSCJ, \\ Universidad de Comillas, \\ Madrid.
}

"Uno es pobre, no sabe nada. Lo único que nos sobra en este mundo es sufrimiento. De eso sí sabemos". Son palabras de una mujer campesina brasileña, recogidas por Carlos Mesters, en su comentario a los cantos del Siervo del libro de Isaías'. Su lectura nos ayuda a contemplar en la figura del Siervo al pueblo "que sabe de sufrimientos", oprimido, desfigurado, no tenido en cuenta, sin apariencia de persona, sin un mínimo de reconocimiento, explotado y despreciado.

Este personaje misterioso, al que se refieren los cualro cantos, aparece en los Ires primeros (Is $42,1-9 ; 49,1-13 ; 50,4-9$ ) como alguien que vive una particular calidad de relación con Dios y con el pueblo. Debe llevar a cabo lo que Dios le confía: proclamación alegre de una buena noticia, «palabra de aliento al abatido», reunión de los dispersos de Jacob, irradiación de una justicia más vivida en su persona que anunciada. Por eso compromete en ello sus palabras, sus actitudes y sus acciones: esa será su manera de conseguir reagrupar al pueblo del Señor y de llegar a ser luz de las naciones.

En el cuarto canto, la situación cambia: si en los otros tres el Siervo es alguien activo que tiene como misión "dictar la ley a las naciones" $(42,1)$; "hacer justicia lealmente, sin desmayar ni quebrarse hasta implantar en la tierra el derecho" $(42,4)$; "abrir los ojos de los ciegos, sacar del calabozo al preso, y de la cárcel a los que viven en tinieblas" $(42,7)$, ahora el Siervo ya no habla, ni proclama, ni consuela, ni anuncia, ni anima: el encargo que se le había confiado lo realiza "soportando", "aguantando". "cargando con", "traspasado y tritura-

1. La misión del pueblo que sufre (Madrid, 1983), p. 131. 
do"... A la palabra del que no quebraba la caña cascada ni apagaba el pábilo vacilante, ha sucedido el silencio total. "Lo que agrada al Señor" se cumple, pero no tanto por él cuanto en él mismo. Ya no actúa, sólo padece las acciones de otros.

Y es sobre todo aquí donde la mirada del lector no puede menos que ver, "superpuestos" sobre el rostro del Siervo, los de un colectivo ingente de seres humanos que hoy pueden ser descritos con sus mismos rasgos.

Esa va a ser la clave de lectura que emplearemos en estas páginas: nos acercaremos al texto focalizando una serie de expresiones, en especial las referidas a la mirada y a la sensibilidad en general, que nos ayuden a realizar esa lectura colectiva que vamos a limitar en este caso a un grupo concrelo de seres humanos: las poblaciones indefensas de Ruanda, Burundi y República Democrálica del Congo, en estos momentos prácticamente o, mejor dicho, "estratégicamente" olvidados?.

2. He tenido la oportunidad de conocer la situación de los habitantes de los Grandes Lagos africanos a través de Juan Carrero Saralegui, presidente de la Fundación S'Olivar, con sede en Estellencs, Mallorca (España), propuesto en este momento como Premio Nobel de la Paz con el apoyo, entre otros, de A. Perez Esquivel. Juan Carrero pertenece junto con su mujer, Susana, a la tercera generación del movimiento de la no-violencia creado por Mahatma Ghandi y seguido por Lanza del Vasto, al que conoció en la comunidad de El Arca. Tercer objetor de conciencia en tiempos del franquismo, se propuso forzar la aceptación legal del servicio social sustitutorio Irabajando tres años (el doble de lo que suponfa el servicio militar) en la escuelita de una aldea quechua, a 4,000 metros. en el norte de Argentina y a unos pocos kilometros de Mina Aguilar. una enorme mina de la que una empresa norteamericana extraía diariamente grandes toneladas de valiosos minerales. Era prófugo de la justicia militar española y su propósito era regresar a España tras esos años de servicio avalado por la Delegación de misiones de su diócesis. Cuando comenzó la represión en Argentina, salvó su vida de milagro, 10 mismo que su mujer y Adolfo Pérez Esquivel. que es ahora el principal promotor, en este momento, de la candidatura de Juan Carrero al Premio Nobel.

Entre sus últimas acciones por la pacificación de Africa Central destacan la marcha a pie a Ginebra, un encuentro en Milán con premios Nobel y 42 dás de huelga de hambre. Recibió el apoyo del parlamento europeo y de 16 premios Nobel y posibilitó que la comisaria europea, Emma Bonino. se desplazara, en febrero de 1997 con cámaras de televisión a los escenarios del genocidio. Carrero denuncia que "el gobierno de Estados Unidos ha formado militarmente a unas fuerzas armadas extremistas de la etria tutsi que están realizando verdadero genocidio de hulus que supera con mucho en barbarie y dimensiones al realizado por éstos últimos en 1994".

Recientemente ha sido distinguido con el premio "Coraje de la conciencia", que concede la Abadía de la Paz, (undada y dirigida por Lewis Randa. El premio recono-

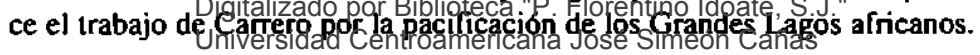


El objetivo es que este tipo de aproximación al texto, a partir de la situación de las víctimas, nos permita participar del "desvelamiento" vivido por el autor del relato. Porque lo que encontramos en el poema no es tanto una descripción de los sufrimientos de un enviado de Dios, sino el testimonio de la conversión en su forma de conocer de quienes contemplaron al Siervo y que, a través de él, transformaron su percepción y su sensibilidad. Y es esa misma transformación la que estamos llamados a actualizar hoy.

\section{Aproximarnos al texto}

Comenzaremos por hacer una lectura del cuarto canto (Is 52, 13-53, 12), utilizando como criterio de separación de párrafos el de quiénes van tomando sucesivamente la palabra.

a) Comienza hablando Dios con una Ilamada de atención hacia su siervo. Anuncia la exaltación de un personaje desfigurado que va a causar asombro y estupefacción.

Mirad, mi siervo tendrá éxito, subirá y crecerá mucho.

Como muchos se espantaron de él, porque, desfigurado, no parecía hombre ni tenía aspecto humano, asł asombrará a muchos pueblos; ante él los reyes cerrarán la boca, al ver algo inenarrable y contemplar algo inaudito.

b) Desde 53,1-6 toma la palabra un "nosotros" coral que va describiendo primero los aspectos más exteriores del Siervo, pasando después a una reflexión más profunda sobre el significado de su sufrimiento: ellos mismos están implicados en el dolor del Siervo.

¿Quién se creyó nuestro anuncio?

¿A quién se reveló el brazo del Señor?

Creció en su presencia como brote, como raíz en tierra árida, no tenía figura ni belleza que atrajera nuestras miradas.

Despreciado y evitado de la gente,

Puedo decir que no había encontrado hasta ahora una confirmación tan evidente de

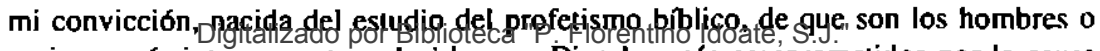

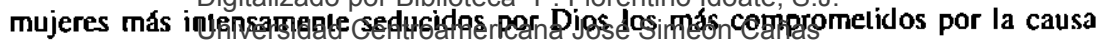
de lo humano, los más contagiados de la pasión de Dios por su mundo. 
un hombre hecho a sufrir, acostumbrado al dolor; al verlo se tapaban la cara; despreciado, lo tuvimos por nada; a él, que soportó nuestros sufrimientos, y cargó con nuestros dolores, le tuvimos por un contagiado, herido de Dios y afligido.

El, en cambio, fue traspasado

por nuestras rebeliones, triturado por nuestros crímenes.

Sobre él descargó

el castigo que nos sana, y con sus cicatrices nos hemos curado.

c) A partir del v. 7, y hasta el 10, ha desaparecido el "nosotros", y el desconocido que habla ahora no se va a fijar en el beneficio producido, sino en las actitudes del Siervo, en su manera de vivenciar internamente los acontecimientos.

Todos errábamos como ovejas, cada uno por su lado, y el Señor cargó sobre él todos nuestros crímenes.

Maltratado, se humillaba, no abría la boca;

como cordero llevado al matadero, como oveja muda ante el esquilador, no abría la boca.

Sin arresto, sin proceso, lo quitaron de en medio, ¿quién mediló en su destino?

Lo arrancaron de la tierra de los vivos, por los pecados de mi pueblo lo hirieron.

Le dieron sepultura con los malvados y una tumba con los malhechores, aunque no había cometido crímenes ni hubo engaño en su boca.

El Señor quiso triturarlo con el sufrimiento; si entrega su vida como expiación, verá su descendencia,

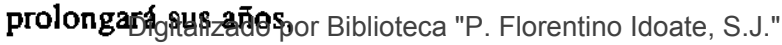


y por su medio triunfará

el plan del Señor.

d) En los dos últimos versos (11-12), es el Señor quien toma de nuevo la palabra para descifrar el sentido de la existencia de su Siervo.

Por los trabajos soportados

verá la luz, se saciará de saber;

mi siervo inocente

justificará a todos

porque cargó con sus crímenes.

Por eso le asignaré

una porción entre los grandes

y repartirá botín con los poderosos:

porque vació su vida hasta la muerte

$y$ fue contado entre los pecadores,

cargó con el pecado de todos

e intercedió por los pecadores.

En el texto aparecen dos planos, dos niveles en la relación con el Siervo, en cuanto a su condición de "hombre de dolores": uno de ellos es el de la apariencia, que provoca repulsión y rechazo; el de sus carencias de belleza y de aspecto humano, que son causa de espanto y distanciamiento. La consecuencia de verlo tan hundido por el dolor es juzgarlo de un modo severo, que no hace sino seguir la doctrina tradicional: es alguien herido por Dios y, por lo tanto, castigado. Se lo puede despreciar y evitar.

Pero, a lo largo del discurso, se produce el descenso al nivel de la realidad que se ocultaba debajo de las apariencias: eso que soporta son "nuestros sufrimientos"; eso que aguanta son dolores nuestros; ese castigo que ha caído sobre él lo merecíamos nosotros, son nuestros pecados los que pesan sobre él.

Se ha producido un des-velamiento y la repulsión ha dejado paso a la atracción; la desfiguración se ha convertido en transfiguración. Se confiesa algo insólito y heterodoxo, que rompe con la teología imperante: a pesar de su quebrantamiento, Dios estaba de su parte, y eso quiere decir algo tan revolucionario como que la fidelidad y la elección de Dios no se rompen con el sufrimiento, y que la bendición no implica necesariamente una vida feliz.

\section{2. "Ante el que se oculta el rostro..."}

Descendamos ahora, aunque sea bruscamente, a nuestro presente, desde la mirada de olro testigo de los sufrimientos del Siervo.

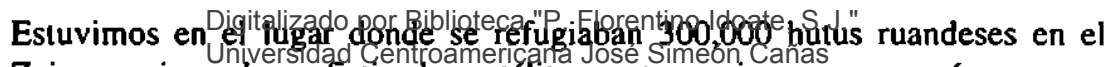
Zaire a quienes los sofisticados satélites norteamericanos no querían ver y a 
los que se negaba la existencia [...] Es increíble lo que está ocurriendo ahora mismo en los Grandes Lagos, en medio de un silencio mediático impresionante. En este momento, la situación ha pasado a convertirse en la mentiral mediática más grande, la causa más dura y más perdida del presente. Para un ghandiano, la mentira es casi tan grave como la violencia, cuando se engaña a la opinión pública, estamos creando los gérmenes de la violencia y somos culpables de ello?.

No nos sorprenden sus palabras: una de las experiencias más frecuentes de la situación de las víctimas es la de la noexistencia, la de no contar. En palabras de Manuel Scorza:

No lo veían porque no lo querían ver. Era invisible, como invisibles eran lodos los reclamos, abusos y las quejas [...] Hablé largo rato. Ni siquiera alzó los ojos... No me vio ${ }^{4}$.

Estamos ante un "calco" de la primera reacción de los que contemplan al Siervo: "ocultar el rostro", y podemos reconocer en ella el rechazo de nuestra sensibilidad ante todo lo que no coincide con los cánones impuestos por una cultura que sólo aprecia lo que encierra poder, belleza o triunfo. Tenemos muchas formas más o menos sutiles de convertimos en expertos en evasión y desentendimiento, de ocultar el rostro ante el dolor ajeno, de evitar a quienes lo padecen, despreciarlos y justificar teológica (o económica, o socialmente) su situación. Y nos hacemos merecedores entonces de una de las peores desgracias que pueden acontecernos: la de la pérdida de sensibilidad ante la alteridad.

¡Ay de aquellos que sólo contemplan

lo bello, sano, poderoso

y no esperan salvación de lo más bajo y humillado,

porque no podrán contemplar la salvación

que brota en el Jesús encarnado desde abajo!s.

Una discípula de E. Levinas, Catherine Chalier, recuerda la preocupación del lilósolo judío por la contemplación del rostro del otro.

En un mundo presa de la violencia y del drama de la indiferencia del hombre por el hombre, sin ojos ni corazón más que para los propios intereses, para verter la sangre inocente y ejercer opresión, el encuentro del rostro aún podría romper la dura corteza que, con demasiada frecuencia, hace de cada cual un ser para sí. Podemos limitamos a analizar un rostro des-figurándolo y, por ello, destruyéndolo como tal al rehusar afrontarlo... Para acceder al significado del rostro hay que dejar de querer imponerse a los otros... El

3. El Muido/El Dia de Baleares, 13 de lebrero del999.

4. Hisloria de Garaboinbo el Invisible (Barcelona, 1972).

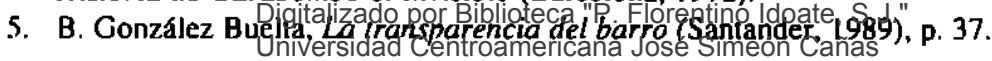


encuentro con el rostro del otro es una epifanía, un acontecimiento que necesariamente sorprende al sujeto, o que le sobrecoge y hace daño. Pero este daño, que se asemeja al dolor de saber que este rostro está amenazado por la violencia y la muerte, no incita a la morbidez: aviva el sentido de la responsabilidad infinita del yo para con el otro. Por su desnudez, el rostro del otro está expuesto a los múltiples peligros que acechan a los que no saben defenderse o socorrerse: su vulnerabilidad anuncia la constante posibilidad de su muerte. Sin embargo, por esta misma razón, mirarlo es oír al punto estas palabras viejísimas y olvidadísimas: "No matarás". Esta resistencia del rostro a la eventualidad del gesto asesino no elimina, por desgracia, la realidad concreta del crimen, y ni siquiera esas formas cotidianas suyas que son el desprecio y la negación del otro de pensamiento, palabra y acto... Estos gérmenes homicidas [...] arraigan en la voluntad de eliminar de la tierra la presencia enigmática de la alteridad .

En una reunión con un grupo de gente de un barrio popular, una señora comenzó a hablar diciendo: "Nosotros, los imaginarios...". Estaba usando para definirse una expresión que habra escuchado con referencia al grupo con el que compartía su identidad y se confundra con la palabra marginado. Pero su expresión era correcta, porque una de las experiencias más fuertes de las víctimas de la cultura de la pobreza es la de la no-existencia ${ }^{7}$.

Hoy contamos con excelentes pretextos para "taparnos el rostro" y Juan Carrero nos avisa sobre distintos tipos peligrosos de "venda".

-Dejarnos engañar por la poderosa campaña mediática que, tras el genocidio de cientos de miles de tutsis y hutus moderados en 1994, ocultan ahora a la opinión pública internacional otro genocidio mucho mayor de varios millones de hutus y justifica el brutal apartheid que sufren los supervivientes de esta etnia mayoritaria. Mons. Munzihirwa, obispo jesuita de Bukavu, tres días antes de ser asesinado, habfa clamado al igual que Mons. Romero: pedimos a los lobbies tutsis que dirigen Rwanda y Burundi que dejen de organizar la desinformación a fin de engañar a la opinión internacional.

-Darle una importancia trascendente a la labor humanitaria cuando, en realidad, las causas del genocidio en Africa central son descaradamente políticas y económicas. Las decisiones se toman en Washington, mientras que en la Unión Europea no existe una política común en materia de relaciones exteriores, lo que hace que Europa sea en estos momentos un gigante de ayuda humanitaria, pero un enano diplomáticamente hablando. En los Grandes Lagos hay unos intereses económicos brutales, se manejan ejércitos, se manejan poderosísimos imperios

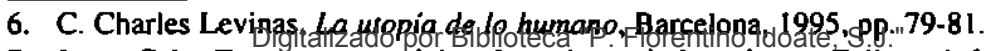

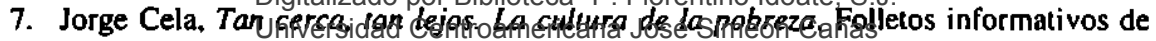
Manos Unidas n 7, Medrid, 1999, p. 25. 
mediáticos y hemos llegado a un extremo en que la gente ha confundido la realidad que nos cuentan los medios de comunicación, con la misma realidad y en medio de esa franja está la opinión pública. Sólo algunos periodistas independientes de Nueva York han denunciado que las grandes corporaciones económicas multinacionales son propietarias del 75 por ciento de los medios de comunicación.

-Quedarnos en la superficie de las situaciones, sin atrevernos a profundizar en sus últimas causas: en estos últimos años se ha constatado un cambio político importante, desde el momento en que Estados Unidos ha mostrado su interés comercial en Africa y lo que ahora está comenzando ahí es un proceso muy semejante a los que surgieron en Latinoamérica durante los años de las dictaduras. Aunque se ha intentado hacerlo pasar como una rebelión interna, lo que realmente ha sucedido es un cambio de dueños en la industria minera. Lo que se nos está vendiendo como una lucha entre etnias rivales, tiene sus raíces en decisiones que se están tomando en Washington. Y cuando el gobierno de Estados Unidos decide algo, casi el único que puede detenerlo y más ahora que es una potencia hegemónica, es su propia sociedad. Quizá no sean conscientes ahora mismo, pero los extremistas tutsis en los regímenes de la región se han excedido tanto que el gobierno norleamericano tendrá serios problemas por haber formado militarmente a estas fuerzas armadas genocidas en sus escuelas de adiestramiento, y por haber estado sobre el terreno cuando se producfan las invasiones, de 1990 en Rwanda y de 1996 en Zaire.

Dice J. M. Fernández Martos que "nacemos con ojos pero no con mirada. Para ver, basta con dirigir los ojos hacia el estímulo en cuestión. Para mirar hay que poner en marcha también el corazón" ${ }^{\prime \prime}$. Y eso supone aceptar nuestra incapacidad para relacionarnos acertadamente con el sufrimiento, nuestra necesidad absoluta de acoger una des-velación de su misterio. Y sospechar que, sin ella, lo más probable es que nos equivoquemos también al mirar en dirección a los que son sus víctimas.

Necesitamos que, como los que se atrevieron a mirar largamente al Siervo y resistieron su primer impulso de alejarse de él, lo mismo que el sacerdote o el levita de la parábola, llegar a ver en él y en ellos las consecuencias de nuestro pecado: de nuestra injusticia, de nuestra inconsciencia, de nuestra cobardía, de nuestro nivel de vida... Era él quien "soportaba nuestros sufrimientos, y cargaba con nuestros dolores", pero para reconocerlo y confesarlo necesilamos tener el of́do abierto de los discípulos para "creer en un anuncio", para escuchar el "mirad a mi Siervo" y dirigir nuestros ojos en su dirección, que es siempre hacia abajo, hacia las tierras áridas donde la vida humana está permanentemente amenazada.

8. J. M. Fernández Martos, "Mirarán al que Iraspasaron. Liberar nuestra mirada cautiva", Sal TerraePpiggeljzags +g\%. Biblioteca "P. Florentino Idoate, S.J."

Universidad Centroamericana José Simeón Cañas 


\section{El peso de lo débil}

Otra dimensión revelatoria que nos ofrece el cuarto canto del Siervo es la de adiestrar nuestros sentidos para que lleguen a distinguir la diferencia cualitativa que existe entre el bien y el mal. La persona de los verbos oscila constantemente entre el plural y el singular; pasa de un "nosotros", de un colectivo que se reconoce pecador, culpable, merecedor de castigo, marchando "cada cual por su camino", a un "él" solitario, el Siervo, que carga con lo de los otros, soporta sus dolores, entrega su vida, intercede por ellos... Y el resultado linal no es que se imponga la desgracia que merecen los numerosos culpables, cubriéndolo todo con la cantidad de su injusticia, sino que todo eso es superado, vencido, "rehabilitado", "justificado" por la calidad del bien de uno solo que es justo.

La pregunta se presentía ya en las argumentaciones de Abraham a propósito de Sodoma y Gomorra en Génesis 18, 16-33:

“De verdad vas a aniquilar al justo con el malvado?

¡Lejos de ti hacer semejante cosa...!”.

Lo que en el fondo se cuestiona es de qué parte está Dios con su juslicia: ¿de la cantidad del mal o de la calidad del bien? Allí la respuesta era que diez justos bastaban para salvar a la ciudad. Aquí se llega más lejos: un solo hombre basta para salvar a todos; el bien pesa más que el mal, cualquiera que sea la cantidad de éste. Porque la justicia de Dios consiste precisamente en el perdón que se da a todos en razón de un inocente.

La sanación de nuestra sensibilidad consistiría en este punto en curar nuestros ojos y nuestros oídos del pesimismo paralizante con que percibimos la realidad. Porque podemos Ilamar "realismo lúcido" a nuestra incapacidad para mirar y escuchar, más allá del estruendo ensordecedor de los gestos de destrucción, violencia y odio que agitan el mundo, el imperceptible murmullo de los innumerables gestos de amor, de capacidad de compartir, de generosidad y de don de sí de tanta gente. $Y$ en ellos podemos seguir reconociendo la entrega hasta la muerte del Siervo y su capacidad de cargar con lo de otros.

Vamos a proyectar esa luz del "uno" que "justifica a muchos" sobre el testimonio de una hermanita de Jesús rwandesa que pertenece a la etnia tutsi y cuya familia fue exterminada por los hutus en 1994.

"Eran los dlas siguientes al genocidio de 1994 y yo andaba buscando una nueva razón para vivir. No sabla por donde reemprender mi vida: como tutsi, tenía que haber muerto, pero me libré y me sentía culpable. El sentido de la vida me parecla como levantar una montaña: tenía que redescubrir el rostro de Dios que estaba muy callado". Un día en Karama, una pequeña aldea,

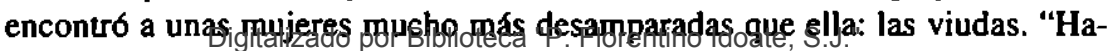
bían perdido surmaridiad Sush hijosiestuafamidia. SAnzecesamse encontraba delante de heridos que no tenían brazos o que les faltaba una pierna. Decidimos 
reunirnos y hablar de lo que habíamos vivido. En abril de 1995, 1056 viudas lanzaron "El corajc de vivir", un proyecto hecho a base de reuniones semanales por grupos de vecinos. Las palabras perdón y reconciliación no se empleaban. Se sabía quién había hecho qué. Las viudas estaban agitadas, querían vengarse, no soportaban ver a una mujer amamantando a su hijo. Sólo queríamos recobrar la confianza en nosotras mismas y aceptar la realidad. Decirnos, sencillamente: Esto viva, soy viuda, mis hijos o volverán". Dejábamos a la gente hablar y llorar, sin moralizar ni dar consejos; descubríamos a las personas que llevaban las heridas más grandes y eso nos curaba. Al principio nos sentíamos culpables y hastiadas de nosotras mismas, como si no fuéramos dignas de vivir en sociedad. Era el tiempo de las alucinaciones. Las viudas oían el grito de un niño que corría por la carretera pidiendo socorro, el redoble de los tambores que precedía a las malanzas, el ruido de la lluvia que caía espesa durante los tres meses de genocidio, las voces de un marido llamando a su esposa. Un psicólogo acompañó las reuniones durante nueve meses y poco a poco las lágrimas se secaron y la frustración se transformó en envidia: las viudas no podían ver una pareja caminando por la calle, una mujer llevando un niño a su espalda. Y el tiempo fue pasando: las viudas acogieron huérfanos, cuatro o cinco mujeres volvieron a casarse. El primer niño de estos matrimonios tiene ahora cuatro meses.

Más tarde emprendimos una reflexión sobre el mal leyendo la Biblia, la pasión y el libro de Job. Yo descubrí que la religión cristiana era ante todo la persona de Jesús y su vida a través del evangelio, antes que los dogmas, la moral o el culto. Un día me dije que no era normal dedicarme únicamente a las viudas. Había mujeres hutus que visitaban cada día a su marido preso. Hable de ello a las viudas y las mujeres de los detenidos dieron el primer paso: su drama era tener un marido criminal, haber vivido con él durante los acontecimientos, saber dónde iba y de dónde venía. Otras decían que su marido era inocente, que no había habido muertos ni genocidio.

Después, en noviembre de 1997, una serie de circunstancias reunieron a los responsables de los equipos. Las viudas y las mujeres de los presos, que se cruzaban sin hablarse en el mercado o en el dispensario, decidieron hacer tarea común. Cuando las viudas empezaron a contar sus sufrimientos, las mujeres de los presos se callaron y este mutismo estuvo a punto de hacer explotar todo. A pesar de todo, algunos grupos decidieron reunirse. En una sociedad donde muchos de los maridos estaban muertos o en la cárcel y los hijos muertos o exilados, estas mujeres tomaron conciencia de su fuerza, cultivando juntas campos comunales. Desde noviembre de 1997 están presididas por Serafina, viuda tutsi, e Inés, mujer de un preso hutu?.

9. François d'Alançon Le Monde 21 de agosto de 1998 (Publicado en el Boletín

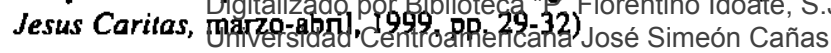


Teo Corral, una carmelita de la caridad, aporta estos rostros del Siervo reflejado en mujeres de Libreville:

Conocí a Tantine Marie después de la muerte dramática de Lucie, una cristiana de nuestra parroquia que no pudo soportar las presiones de su marido y se suicidó. Tantine Marie, en cambio, está orgullosa de su marido y habla de él con frecuencia. Cuando un día le pregunté: “¿Cuántos hijos tienes?”. Dirigió una mirada furtiva a su vientre y dijo: "Tengo muchos". Su mirada la Iraicionó: en efecto, nunca pudo tenerlos: cinco abortos y tres operaciones sin resultado posilivo. "Pero, añade Tantine, a pesar de ello soy feliz, espero siempre de Dios un hijo de mis entrañas, El sólo conoce el momento. Y, además, mira por qué caminos me ha hecho madre: me ha dado los hijos de Lucie. Son mis hijos. Cada día le pido a Dios: Dame mucho amor, mucha fuerza y valor para educar a mis hijos..."

No las conté, pero me impresionó la cantidad de veces que Tantine habló de corazón, ternura, amor... Me dije que esta mujer ha sabido desplazar del útero al corazón el espacio de fecundidad. Porque la lecundidad es, ante todo, un asunto de amor.

Sylvie vive en su propia carne el drama de muchas mujeres: "Mi marido me viola cada vez que hacemos el amor. Está celoso porque voy a la parroquia, Ine insulta por ello y se venga haciéndo el amor con violencia, como si quisiera matarme. Cuando me quedo embarazada, me da patadas en el vientre porque, según él, vete a saber de quién será este niño. Enlonces yo me curvo en dos para proteger el vientre con mis manos. Este niño me lo ha dado Dios y debo protegerlo". El cuerpo de Sylvie, marcado por una violencia brutal, se convierte a diario en un cuerpo que derrocha ternura, comprensión y consejo a su alrededor ${ }^{10}$.

Todo este trabajo inaudito de reconciliación, toda esta mansedumbre y esta fortaleza, aunque parezca minoritario, "pesa" más que lodos los odios y está justificándonos. Nuestra humanidad sigue teniendo a Dios de su parte, porque en su Hijo está viendo la belleza de todos los que se le parecen y que son los que nos siguen curando con sus heridas.

\section{Unos medios desconcertantes}

Otra dimensión revelatoria: la mirada dirigida a un nivel más profundo que el del hacer: los que contemplan al Siervo acceden a un conocimiento diferente que les permite diferenciar "eficacia" de "fecundidad" y comienzan a ser capaces de descubrir de qué hondura de la persona nace ésta.

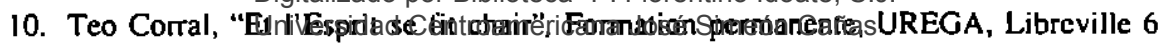
de marzo de 99. 
En los otros tres cantos, el Siervo es alguien activo que debe "dictar la ley a las naciones" $(42,1)$; "hacer justicia lealmente, sin desmayar ni quebrarse hasta implantar en la tierra el derecho" $(42,4)$; tiene que "abrir los ojos de los ciegos, sacar del calabozo al preso, y de la cárcel a los que viven en tinieblas" $(42,7)$; aunque en medio de dificultades, siente que Yahvé lo ayuda y que nadie puede condenarlo $(50,8-9) \ldots$

Todo ha cambiado en el cuarto canto: aquí el Siervo ya no habla, ni proclama, ni consuela, ni anuncia, ni anima: el encargo que se le había confiado lo realiza "soportando", "aguantando", "cargando con", "traspasado y triturado"... A la palabra del que no quebraba la caña cascada ni apagaba el pábilo vacilante, ha sucedido el silencio total.

"Lo que agrada al Señor" se cumple, pero no tanto por él cuanto en él mismo. Ya no aclúa, sólo padece las acciones de otros.

El "brazo del Señor", que debía operar un nuevo éxodo $(40,10)$, interviene ahora en el destino misterioso del Siervo; la tierra desolada del desierto, que se iba a transformar en hontanar de agua $(41,18)$, es ahora de donde sale él como una raicilla.

En el siervo sufriente, la comunidad dispersada se deja reunir, y es ahora realmente cuando cumple el encargo que habla recibido y se convierte en "luz de las naciones", porque les consigue la justificación.

Ante el comentario sobre lo mínimo de los comienzos a la hora de sensibilizar a la opinión pública sobre los problemas de los Grandes Lagos, Juan Carrero comenta:

Ahora se está viendo la eficacia pero, cuando comencé, la verdad es que dudaba mucho de los resultados. Lo que ha dirigido siempre mi vida es una certeza interna, más que un concepto de eficacia. Hemos pasado momentos muy duros de incomprensión, hasta de calumnias, y los hemos pasado igual que ahora pasamos el momento del premio. Quienes creemos en la no violencia y la paz, tenemos una gran ventaja, porque ese nivel espiritual del que hablaron Ghandi y Martin Luther King no es una creencia en algo lejano, sino una experiencia cotidiana. Yo sé, aunque no sea capaz de formularlo, que hay algo más que lo visible, y por eso mismo me apunto a aquella frase que usaban amigos míos muy queridos en Latinoamérica, y es que "nosotros no estamos amenazados de muerte, sino de resurtección". Eso da un modo de funcionar muy especial y una liberlad enorme para decir a quien sea lo que haga falta".

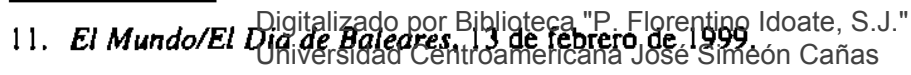


La contemplación del Siervo y de la eficacia de su entrega por caminos alternativos a la acción eficaz y verificable, posibilita el dedicar energías y recursos a la misma causa a las que él las dedicó, pero contando con que todo eso tiene un "más alla", apoyando en él la oscura certidumbre de que hay palabras que tienen más fuerza cuando nacen del silencio; que existe ganancia cuando parece que está perdiendo inútilmente la vida y las fuerzas:

Hace dos años emprendimos una huelga de hambre de 42 días, primero en Estrasburgo y después en Bruselas y recibimos el apoyo de 19 premios Nobel y del parlamento europeo. Lo más importante fue que la comisaria Emma Bonino, al noveno día de nuestro ayuno, decidió acudir al Congo con las cámaras de televisión y que apareciesen imágenes de aquellos refugiados a quienes se negaba la misma existencia. Después, el gobierno de Estados Unidos pidió disculpas, alegando que tenía mal enfocados sus satélites. Pero allí estaba la caravana inmensa de 300,000 personas sólo en Tingui Tingui. Aquello fue una denuncia pública muy importante, porque a los refugiados se les negaba la existencia, evidentemente con el objetivo de facilitar su exterminio. A pesar de ello, a pesar de la presencia de las cámaras, la política de Estados Unidos siguí inflexible, o como mínimo, prestando su apoyo a unos extremistas tutsis que ya tenían decidido eliminarlos. Al menos se consiguió salvar al 15 por ciento de aquel medio millón de refugiados ${ }^{12}$.

\section{5. "Sus heridas nos curaron"}

Finalmente, un último movimiento del texto orienta nuestra obediencia en dirección al camino que ha conducido al Siervo a la glorificación. Desde el comienzo se anuncia el triunfo de alguien en quien se da algo "inenarrable e inaudito", algo que consigue enmudecer y asombrar a todos. La mirada que, según la lógica humana, se dirige hacia arriba (¿no va a "subir" y a "crecer"?), es obligada a volverse hacia abajo, a ras de suelo, y a contemplar la no-belleza, la no-apariencia, la no figura.

Pero la transfiguración no se opera en la apariencia externa, sino en el secreto que se descubre a partir de la actitud interior del Siervo: "vació su vida hasta la muerte" e "intercedió por los pecadores". La primera raíz hebrea empleada, ' $R H$, significa "desnudar vaciando". En Génesis 24,20 es "vaciar un cántaro", una imagen cercana a la sangre derramada. Paredozen, "se entreg6", traducirán los LXX; ekenosen "se vacio", dirá Pablo, en Filipenses 2, 7.

La segunda, $P G$ ', tiene el sentido de "encontrarse con alguien", "solicitar", "interceder", pero no tanto en la oración cuanto en un "hacer presión", "intervenir", "interponerse", como Moisés en la brecha, en el Salmo 106, 23.

Digitalizado por Biblioteca "P. Florentino Idoate, S.J."

12. Ibid.

Universidad Centroamericana José Simeón Cañas 
Al final escuchamos, por tanto, lo que era in-audito; sólo al final se proclama lo in-enarrable: alguien se ha identificado tanto con sus hermanos que ha vaciado su vida en la muerte por causa de ellos.

Alguien se ha com-padecido tanto de ellos y con ellos que ha cargado con todos sus pesos. Alguien los ha querido tanto que se ha inter-puesto, se ha puesto en su lugar.

$Y$ tan poderosa es la fuerza de su solidaridad que, gracias a ella, los culpables quedan libres de su falta; los pecadores, perdonados; los dispersos se reúnen; $y$ los que juzgaban por apariencias, ahora se acercan al Siervo, lo contemplan, reconocen su inocencia, descubren y confiesan lo que antes estaba oculto a sus ojos.

Eso significa aceptar que la calidad de lo humano se mide por su capacidad de solidaridad. Que lo que hoy y siempre provoca asombro, arrastra y convence de alguien, no es su decir, ni su hacer, ni su emprender, ni su predicar, sino su disposición a vincular su vida a la de los otros, a hacerse cargo y encargarse y cargar con lo que los agobia y los pesa y les impide ser libres y felices.

Hemos visto cómo en los que contemplan al Siervo se da un "descenso de nivel", en cuanto a su comprensión del significado de su prueba. Sólo en ese segundo momento llegan a entender que su disposición interna hacia ellos ("se entreg6", "intercedio", dice el texto; "solidaridad", traducimos nosotros), que antes no habían sido capaces de descubrir, era el elemento clave que lo explicaba todo. Podríamos decir que ése es el elemento unificador entre las etapas anteriores más "activas" de su misión y la que describe el cuarto canto. En éste, una de las dimensiones de su "aguante" consiste en permanecer fiel en su voluntad de vinculación y de servicio, incluso cuando lo más hondo de su actitud hacia los otros no es reconocida.

El amor es fecundo también en sus fases de "latencia", y entonces es cuando se enraiza y se cimenta y se verifica; que, aunque resulte una locura, hay que seguir intentando, como él, vivir abiertos y vulnerables; y que en ese querer, y esperar, y echar raíces en la voluntad de entrega, está el camino escondido por el que podemos llegar a "ver la luz", "saciarnos de conocimiento" y "Ilevar a término lo que el Señor quiere".

Mucha gente sigue hoy viviendo desde ahi y es uno de los mayores dones del Espírilu el llegar a percibir ese rumor en medio del estrépito ensordecedor de los aclos de odio, de violencia y destrucción que agitan el mundo. Desde esa otra "longitud de onda", que da la esperanza, es posible percibir el imperceptible murmullo de los innumerables gestos de amor, de entrega, de compartir solidario, presentes en tantos "lugares de abajo" de la historia. 
Y es posible también contemplar, maravillados, cómo se opera una fantástica transformación gracias a la cual, todo el potencial de salvación que encierran esos gestos de amor, se libera y envuelve al mundo con un manto invisible, como un bálsamo vivificante, derramado sobre sus heridas ". Unas heridas que nos curan.

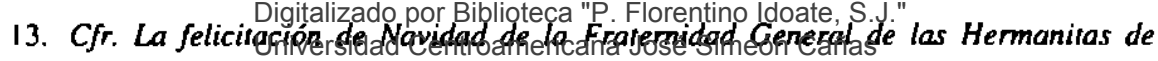
Jesús, Roma. 1996 